\title{
MEMÓRIAS SUBMERSAS: análise sobre as memórias coletivas na formação do reservatório de Itaipu ${ }^{1}$
}

\author{
MEMORIAS SUBMERSAS: análisis sobre las memorias colectivas en la \\ formación del reservorio de Itaipú
}

\section{SUBMERGED MEMORIES: analysis on the collective memories in the Itaipu reservoir formation}

Aracelli Bianchin ${ }^{2}$

Bruno César Alves Marcelino ${ }^{3}$

\begin{abstract}
Resumo
Este artigo compõe uma investigação inicial que buscou identificar o enquadramento da memória coletiva sobre a formação do Reservatório de Itaipu do lado brasileiro. Trata-se de uma pesquisa composta por revisão bibliográfica, que também utilizou como fonte de dados mídias digitais e visita a dois atrativos turísticos da Usina Hidrelétrica de Itaipu. Conclui-se que o enquadramento da memória sobre o processo de formação do Reservatório Itaipu não inclui toda a história. Embaixo d'água estão as ruínas e muitas memórias de lutas e das comunidades que a história oficial deixou de contar. Mecanismo que representa o impasse entre memória e esquecimento e que exprime, a reconstrução seletiva do passado como estratégia política. As memórias sociais coletivas da região alagada encontram-se submersas.
\end{abstract}

Palavras-Chave: Reservatório de Itaipu; memórias; enquadramento.

\section{Resumen}

Este artículo compone una investigación inicial que buscó identificar el encuadramiento de la memoria colectiva sobre la formación del Represa de Itaipú del lado brasileño. Se trata de una investigación compuesta por revisión bibliográfica, que también utilizó como fuente de datos medios digitales y visita a dos atractivos turísticos de la Usina Hidroeléctrica de Itaipú. Se concluye que el encuadramiento de la memoria sobre el proceso de formación del Embalse Itaipú no incluye toda la historia. Bajo el agua están las ruinas y muchas memorias de luchas y de las comunidades que la historia oficial dejó de contar. Mecanismo que representa el impasse entre memoria y olvido y que expresa, la reconstrucción selectiva del pasado como estrategia política. Las memorias sociales colectivas de la región inundada se encuentran sumergidas.

Palabras claves: Represa del Itaipu; recuerdos, marco.

Abstract
This article compiles an initial investigation that sought to identify the framework of the collective memory on the formation of the Itaipu Reservoir on the Brazilian side. It is a research composed by bibliographical revision,

\footnotetext{
${ }^{1}$ Artigo apresentado no Simpósio Temático Repensar, Refletir, Interpretar e Reinterpretar a Memória, identidade e o patrimônio cultural da América Colonial durante o II Seminário Latino-Americano de Estudos em Cultura SEMLACult em Foz do Iguaçu/PR, Brasil, 2018.

2 Mestra em Integração Contemporânea da América Latina; Universidade Federal da Integração LatinoAmericana - UNILA; Foz do Iguaçu, Paraná, Brasil; bianchin.aracelli@gmail.com.

${ }^{3}$ Doutorando em Estudos Sociais Interdisciplinários de Europa e América Latina, Mestre em Integração Contemporânea da América Latina; Centro Latino-Americano de Estudos em Cultura - CLAEC; Bolsista do Centro Universitário Argentino-Alemão - CUAA/DAHZ; Foz do Iguaçu, Paraná, Brasil; brunomarcelino@claec.org.
} 
which also used as data source digital media and visit to two tourist attractions of the Usina Hidroeléctrica de Itaipú. It is concluded that the memory framework on the Itaipu Reservoir formation process does not include the whole history. Underwater are the ruins and many memories of struggles and communities that the official story no longer counts. Mechanism that represents the impasse between memory and forgetfulness and that expresses, the selective reconstruction of the past as a political strategy. The collective social memories of the flooded region are submerged.

Key words: Itaipu Reservoir; memoirs; framework.

\section{Introdução}

O território hoje denominado região lindeira ao Lago de Itaipu no Estado do Paraná, zona de fronteira com o Paraguai, configurou-se a partir das relações construídas ao longo da história. Dos índios guaranis à atual sociedade pós-moderna, esse espaço foi sendo transformado e reconfigurado na esfera social, política, econômica, ambiental e cultural.

Na década de 1940, com processo de ocupação de terras (Marcha para o Oeste) o território passou por diversas alterações socioespaciais. Mais tarde, em 1970, com a crescente industrialização no Brasil, que demandou maior infraestrutura de transporte e energia, a região foi palco de um processo que alterou não apenas sua forma, mas teve efeitos significativos na esfera social, econômica, ambiental e cultural com a construção da Usina Hidrelétrica Itaipu, atual maior usina geradora de energia do mundo.

A formação do Reservatório de Itaipu inundou grandes áreas habitadas, de lavoura e mata virgem no Brasil e Paraguai. Do lado brasileiro, cerca de 40.000 mil pessoas foram atingidas pela desapropriação e deslocaram-se, obrigatoriamente, para outras localidades, "Itaipu significou um momento de desterritorialidade e que, por conseguinte, territorializou áreas como também reterritorializou outras" (SOUZA, 2008). Essa dinâmica condicionou e recondicionou comunidades, intervindo diretamente nas relações sociais, e consequentemente na configuração das memórias e da identidade.

Diante disso, este artigo propõe identificar o enquadramento da memória coletiva sobre este processo. Considera como recorte a dimensão do lado brasileiro, atingida pela formação do Reservatório de Itaipu. Trata-se de uma pesquisa inicial, composta por revisão bibliográfica, que utilizou como fonte de informações, comentários coletados em mídia digital (site), que exibiram uma reportagem sobre a antiga vila de Itacorá, local completamente atingido pela formação do Reservatório. Também contempla na metodologia visitas a campo, isto é, visita aos dois atrativos turísticos da Usina Hidrelétrica de Itaipu: Ecomuseu e Visita Panorâmica ${ }^{4}$.

Analisar os contextos sociais da memória permite entender as forças que atuaram no enquadramento como instrumento político. No processo de formação do Reservatório identificam-se duas forças opostas que polarizaram conflitos: de um lado a visão do desenvolvimento e do progresso expressa pelo Estado Nacional, que declarou que as pessoas atingidas pela formação do Reservatório estariam se sacrificando pelo país, sendo, portanto, patriotas (GERMANI, 2003). Do outro lado, e a partir do "sacrifício" molda-se a outra força, isto é, a resistência da população, a qual, sem possibilidade de escolha, deveriam deixar suas propriedades. Esse campo de forças culminou em manifestações populares e representações de luta que a memória coletiva de poder, a memória nacional, não incluiu.

Sacrificar-se exigia deixar seu o lugar, seu espaço de sociabilidade, de sentido e, romper os vínculos. Sentimentos que se traduzem no relato de um dos líderes do Movimento

\footnotetext{
${ }^{4}$ As visitas foram realizadas em nos dias 20 e 21 outubro de 2016.
} 
Justiça e Terra, Oreste Gasparini (1981), "regressamos aos nossos lares, que já não são nossos, e de lá continuaremos a nossa luta" (GERMANI, 2003). Essa situação gerada pela formação do Reservatório é mais profunda, uma vez que implica diretamente na autonomia do indivíduo.

Identificou-se que as narrativas da história individual, vivida pelas comunidades e pessoas atingidas pela formação do Reservatório, não compõem a memória oficial contada a milhares de turistas que visitam a região e a Usina Hidrelétrica de Itaipu. Haja vista a representação da obra que traduz não apenas a grandeza, mas a própria representação do poder e do contexto político da ditadura que atuou na reconstrução seletiva da memória na intenção esconder os conflitos para não abalar a imagem criada do processo.

Em decorrência, faz-se necessário salientar que o que é oficialmente lembrado tem muita representatividade uma vez que tende a solidificar-se no bojo social e induz as ações futuras. Se as narrativas das memórias das comunidades e as individuais fossem incorporados à memória coletiva, talvez poderiam escrever outro futuro ou ao menos, tecer uma reflexão mais abrangente do passado, servindo as futuras gerações como elemento de aproximação mais realista com a realidade vivenciada no contexto da construção do reservatório.

\title{
2. Desconstrução - e a água inundou
}

A construção da história humana e das memórias coletivas é um processo fluído, não se reduz as decisões econômicas e políticas, mas se faz todos os dias no cotidiano da vida humana e por cada indivíduo. Neste sentido, Halbwachs (2003) afirma que a memória individual existe a partir da memória coletiva, isto significa que, a memória é construída em grupo, portanto, a lembrança de cada pessoa está inserida num contexto social.

As áreas atingidas pelo Reservatório de Itaipu, eram espaços vivos de sociabilidade, marcados pelas pessoas que o habitavam. Os grupos sociais das localidades atingidas determinavam a forma e ocupação do espaço, davam sentido e significado para as construções, criavam laços de afeto com o material e com o imaterial do lugar, constituindo a memória coletiva, conforme cita a autora:

\begin{abstract}
...são os valores de quem vive a intimidade dos lugares, onde antes verdejavam pastagens, onde os trigais douravam as planícies e colinas, onde brotava flores e frutos em abundância. (...) é a imagem de tudo submerso, da igreja construída em mutirão, do local onde realizavam os churrascos, as festas, os encontramos nos finais de semana, da escola erguida com muito sacrifício, das ruas, árvores, cheiros, gostos, cada objeto, de tudo que estava impregnado na história. (RIBEIRO, 2002, p.39 e 49)
\end{abstract}

$\mathrm{Na}$ expressão da autora notam-se detalhes da vida das comunidades nas áreas atingidas, elementos essenciais, que muitas vezes não são abrigados pela história, a qual pontua apenas os fatos relevantes indicados pela sociedade. No entanto, é importante pontuar que as memórias, são os resultados da interação com os fatos, os quais encontram-se com os indivíduos que foram parte da história (HALBWACHS, 2003). Por isso, é preciso compreender que "a memória não é um instrumento para a exploração do passado; é, antes, o meio. É o meio onde se deu a vivência, assim como o solo é o meio no qual as antigas cidades estão soterradas" (BENJAMIN, 1993, p. 239).

História e memória se confundem. A primeira é amparada na segunda, sendo que a memória permite imprimir a história, portanto, se dá quando a memória social acaba, costuma ser o registro, isto é, narrativas, documentos e outros, sendo um processo que perpassa o 
racional, sendo frio e impessoal, "a história, enquanto operação intelectual, dessacraliza a memória" (DEALESSIO, 1993 apud NORA), diferente da memória que é vivida, sentida. A memória coletiva social por meio do indivíduo e, especialmente do grupo, resgata o que está submerso, podendo reescrever e mexer na história. No entanto, a memória coletiva social acaba quando grupo de suporte deixa de existir.

Assim, olhar para o processo do alagamento das áreas pelo Reservatório de Itaipu a partir da memória coletiva significa trazer à tona lembranças do campo de forças, os esquecimentos, os silêncios, aportando para as memórias subterrâneas entre o esquecimento e a memória social.

Pollak chama atenção para os processos de dominação e das relações de poder, apresentando a fragmentação entre memória oficial e dominante e o que ele chamou de memórias subterrâneas. $\mathrm{O}$ autor as referência às camadas populares e destaca sua importância a partir da história oral, "ao privilegiar a análise dos excluídos, dos marginalizados e das minorias, a história oral ressaltou a importância de memórias subterrâneas que, como parte integrante das culturas minoritárias e dominadas, se opõem à "Memória oficial", no caso a memória nacional" (1989, p.2). Assim, considerar essas memórias subterrâneas não é apenas um ato de registro, mas significa dar valor e visibilidade incorporando-as à história. Como afirmou o autor, essas memórias "que prosseguem seu trabalho de subversão no silêncio e de maneira quase imperceptível” (POLLAK, 1989, p.15).

Le Goff também reconhece que na interface memória e história há um processo, ora invisível, de hierarquia. Para ele, a memória é parte da história das sociedades "das classes dominantes e das classes dominadas, lutando todos pelo poder ou pela vida, pela sobrevivência e pela promoção" (1996, p. 475). Essa abordagem aplicada a construção da Usina de Itaipu permite entender o processo de enquadramento da memória, visto que o contexto foi marcado por conflitos e pela atmosfera da ditadura.

O período de desapropriação das terras atingidas pela formação do reservatório de Itaipu se deu entre 1978 a 1982, atingiu 8.519 propriedades em 08 municípios do lado brasileiro, sendo que $81 \%$ das propriedades encontravam-se na área rural. Estima-se que cerca de 40.000 mil pessoas foram atingidas pela formação do Reservatório, 45 templos religiosos e 95 escolas (GERMANI, 2003). O município que teve o maior percentual de área alagada foi Santa Helena (PR). Além disso, vilas inteiras ficaram embaixo d'água, como a Vila Itacorá, antigo distrito do município de São Miguel do Iguaçu.

A formação do Reservatório também inundou o atrativo turístico natural localizado no município de Guaíra (PR), as Sete Queda do Iguaçu. A formação rochosa e as águas desenhavam uma paisagem única de beleza natural, reconhecida nacionalmente. A perda das Sete Quedas provocou intenso luto, visto que, as águas levaram o ícone de maior representatividade da identidade local, atuando diretamente na auto estima dos moradores e nas relações sociais (SANTOS, 2006).

Tal luta e luto podem ser vistos no movimento Quarup ${ }^{5}$ que buscou chamar atenção, contrapondo a visão estabelecida do sacrifício pelo progresso do país e, manifestou a não aprovação do projeto de Itaipu, conforme cita o documento, Carta Protesto: "Sete Quedas vai acabar (...) a obra que a natureza levou milhões de anos para construir não existirá mais. Em seu lugar, haverá um grande Lago de 1350 quilômetros quadrados. Isso é bom ou mau para o Brasil?

\footnotetext{
${ }^{5}$ Palavra que referencia um ritual indígena que imortaliza o defunto, o qual, no movimento, é representado pelas Sete Quedas. O slogan do festival foi: Adeus Sete Quedas: Sete Quedas viverá... Até debaixo d'água.
} 
Quarup foi um movimento de expressão da população que mobilizou cerca de 300 mil ecologistas, 30.000 turistas e 700 mil moradores de Guaíra (SANTOS, 2006). O "Adeus a Sete Quedas" também foi referenciado pelo poeta Carlos Drummond de Andrade (1983). No entanto, o poeta Galvão chama atenção por referenciar a memória, conforme mostram trechos do poema No Ventre das Águas.

No fundo deste rio
existe uma cachoeira
bem guardada, cuidada e
preservada pela natureza
que a criou.
Na gente da cidade
existe um sentimento,
uma espécie de lamento
que não sai do pensamento.
É a saudade que ficou!
(...)Resta a lembrança
Deste tempo que passou. (...)(GALVÃO apud SANTOS, 2006, p. 71).

Não distante das Sete Quedas, os agricultores que perderam suas terras, também organizaram-se para lutar pelos seus direitos e pelo preço justo das indenizações pelas suas propriedades. A falta de clareza no processo de desapropriação somada a todo os sentimentos de insegurança e medo, estimularam que os expropriados se organizassem em 1978, culminando na manifestação popular de dois acampamentos (GERMANI, 2003). Aqui cabe acrescentar como é feita a leitura da resistência, isto é, como os atores proponentes da luta e da resistência são reduzidos ao papel de vítima. Isso se dá uma vez que a atenção concentra-se na dor e não na força de resistir (GROSSMAN, 2000).

Tais fatos têm grande peso na memória coletiva e conectam-se com a visão de Le Goff (1996) sobre a memória como instrumento e objeto de poder, visto que no contexto havia muita tensão, e o país encontrava-se sob o regime militar. Portanto, eleger o que deve ser lembrado e o que deve ser esquecido, representa um embate de memórias, o impasse entre memória e esquecimento e o uso de memória como instrumento político.

Bordieu quando aborda sobre o poder simbólico apoia-se na mesmo entendimento ao afirmar que "as relações de comunicação são, de modo inseparável, sempre, relações de poder que dependem, na forma e no conteúdo, do poder material ou simbólico acumulado pelos agentes" (2001, p.11). Deste modo, os instrumentos simbólicos representam ícones que servem para traduzir a realidade, no entanto, o poder do símbolo não está contido apenas no sistema simbólico, mas no espectro do campo em que atua, isto é, depende da relação de quem exerce o poder e de quem recebe, reproduzindo a crença (BORDIEU, 2001, p 14-15).

A partir do exposto e pautando-se na afirmação de Le Goff que defende que "a memória é um elemento essencial do que se costuma chamar identidade, individual ou coletiva, cuja busca é uma das atividades fundamentais dos indivíduos e das sociedades de hoje, na febre e na angústia" (1996, p. 476). Isto torna claro que o enquadramento da memória possibilita reconstruir identidades, visto que representa a base para o indivíduo para seguir a 
vida com coerência enquanto passa pelo processo de reconstrução de si. Para isso, a memória exerce um papel fundamental na medida em que atua como sentimento de identidade: se reconheço meu passado, sei quem sou (POLLAK, 1992).

Dessa forma, a identidade liga-se as experiências, as lembranças e aos vínculos afetivos, revelando o pertencimento a um determinado coletivo social, "nos recônditos da memória residem aspectos que a população de uma dada localidade reconhece como elementos próprios da sua história, da tipologia do espaço onde vive, das paisagens naturais ou construídas" (PELEGRINI, 2006, p.116).

A memória coletiva social é produzida a partir dos vínculos. Neste sentido, o processo de desapropriação representa um rompimento dos vínculos, é uma ação difícil, pois implica interferir na autonomia do outro e, o que altera na sua identidade. Neste sentido, Mazzarollo alertou que o homem do campo identifica-se com o seu trabalho e com o chão do qual faz brotar o sustento de tantos. Arrancá-lo do chão rural, empurrando-o para o êxodo incerto em direção às cidades (...) é desrespeitar seus direitos (...) é produzir um perigoso desequilíbrio na sociedade (MAZZAROLLO, 2003, p.39)

Um efeito deste processo sobre a memórias das pessoas que o viveram, pode ser interpretado nos comentários que 14 pessoas fizeram sobre uma reportagem exibida em 12/08/2006, com o título: Itacorá e as cidades submersas, do autor Aluizio Ferreira Palmar, no site Usina de Letras ${ }^{6}$. A saber:

\footnotetext{
${ }^{6}$ Disponível em: https://www.usinadeletras.com.br/exibelotexto.php?cod=41562\&cat=Artigos\&autor=Aluizio\%20Ferreira\%20Pa lmar. Acesso em 20 out. 2016.
} 


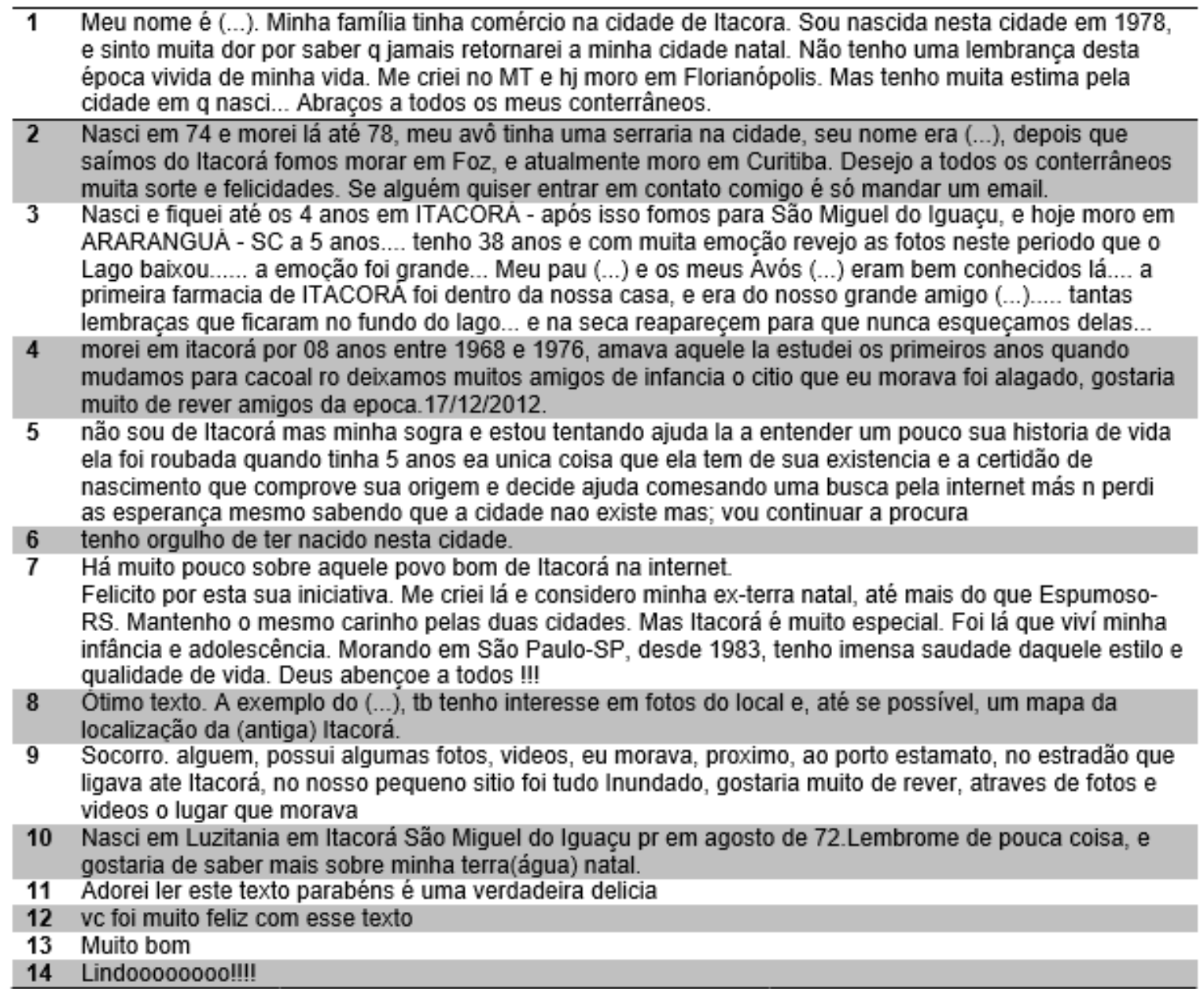

Observa-se nos comentários expressões de emoções e sentimentos de orgulho: "Tenho orgulho de ter nacido nesta cidade"; saudades: "tenho 38 anos e com muita emoção revejo as fotos neste periodo que o Lago baixou...... a emoção foi grande"; traduzindo a relação de afeto das pessoas com o local, "Itacorá é muito especial. Foi lá que viví minha infância e adolescência”.

Nota-se lamentos sobre a história que não foi contada: "Há muito pouco sobre aquele povo bom de Itacorá na internet"; "tantas lembraças que ficaram no fundo do lago... e na seca reapareçem para que nunca esqueçamos delas". Quando a água baixa as ruínas aparecem e com elas emergem as memórias.

As pessoas que comentaram a reportagem, revelam um desejo de buscar registros do local, e mais que isso de comunicar-se, de resgatar as memórias, de buscar elementos de identificação, ao divulgarem seus email e se colocarem disponíveis para contato: "Socorro. alguem, possui algumas fotos, videos, eu morava, proximo, ao porto estamato, no estradão que ligava ate Itacorá, no nosso pequeno sitio foi tudo Inundado, gostaria muito de rever, atraves de fotos e videos o lugar que morava"; "(...), th tenho interesse em fotos do local e, até se possível, um mapa da localização da (antiga) Itacorá."; "Lembrome de pouca coisa, e gostaria de saber mais sobre minha terra(água) natal"; "Se alguém quiser entrar em contato comigo é só mandar um email".

Identifica-se que as pessoas, mesmo sem se conhecerem, se conectam pelo que há de comum entre elas, o lugar que compartilharam em determinada fase da vida. Isso promove a questão da identidade: "Abraços a todos os meus conterrâneos". 


\title{
3. A reconstrução a partir dos alicerces selecionados
}

Todo enquadramento de memória depende dos conteúdos e materiais fornecidos pela história (POLLAK, 1989). Como elemento do social, a memória não se reduz a impressão do passado, pois pulsa vivacidade em seu interior. No entanto, o indivíduo seleciona o que quer esquecer e o que deseja lembrar. Portanto, construir ou reconstruir memórias implica a ação de fazer escolhas, compondo o pensamento histórico, conforme reitera o autor:

\begin{abstract}
... a memória longe de ser meramente um receptáculo passivo ou um sistema de armazenagem, um banco de imagem do passado, é, isto sim, uma força ativa, que molda; que é dinâmica - o que ela sintomaticamente planeja esquecer é tão importante quanto o que ela lembra - e que ela é dialeticamente relacionada ao pensamento histórico, ao invés de ser apenas uma espécie de seu negativo (SAMUEL, 1989, p.44)
\end{abstract}

Para escolher o que lembrar ou esquecer é preciso conhecer. Dessa forma, a reconstrução do passado, isto é, os suportes para lembrar e fixar no presente qualquer experiência, exige lidar com a responsabilidade de construir o futuro:

\begin{abstract}
A fronteira entre o dizível e o indizível, o confessável e o inconfessável, separa uma mesma memória coletiva subterrânea da sociedade civil dominada ou de grupos específicos, de uma memória coletiva organizada que resume a imagem que uma sociedade majoritária ou o Estado desejam passar ou impor (POLLAK, 1989, não paginado).
\end{abstract}

Em visita à Itaipu Binacional, identificou-se que os principais registros da memória oficial ou suportes de memória dominantes são encontrados na forma escrita, oral e audiovisual, esta última por meio da fala dos guias, no Ecomuseu. Este atrativo foi criado em 1987 como "uma das medidas mitigadoras do impacto decorrente da construção da usina, visando a salvaguarda de acervo representativo dos estudos, pesquisas e inventários realizados por Itaipu antes, durante e após a formação do seu reservatório" (Site oficial da ITAIPU BINACIONAL). De acordo com o guia do passeio, o local costuma receber anualmente a visita de alunos dos diversos níveis de escolaridade. De acordo com registros divulgados pela usina, o número de visitantes tem crescido anualmente, atingindo mais de 1 milhão em $2018^{7}$.

O filme exibido no início dos passeios não apresenta os registros dos conflitos, das lutas e das comunidades que ficaram submersas. $\mathrm{O}$ filme trata o fato do enchimento do lago, em um tempo menor que o calculado, como uma benção de Deus, devido as fortes chuvas no período. O discurso nas visitas turísticas é replicado para milhões de brasileiros todos os anos. Trata-se de uma versão hegemônico, contada por uma só voz.

É visto que diante de um governo de regime militar e do contexto de conflitos, foram elegidos suportes de memória que pudessem proteger o Estado e reforçar a visão da construção como apoio ao desenvolvimento econômico do país. De fato, Itaipu foi uma construção audaciosa, com alto nível de tecnologia para a época, mas não se pode ignorar todo

processo.

A reconstrução da memória coletiva social não abriga a diversidade, encontra-se

\footnotetext{
${ }^{7}$ Fonte: https://www.itaipu.gov.br/sala-de-imprensa/noticia/itaipu-projeta-receber-mais-de-1-milhao-devisitantes-em-2018
} 
limitada não apenas pela dificuldade em buscar as memórias, como pelo contexto no qual se localiza, onde a configuração da memória coletiva já permeia a cultura, ou seja, a memória enquadrada, tende a manter-se sob o controle das instituições e não incorporar os conteúdos das histórias individuais. No entanto, para além dos suportes de memória oficiais, há a rica vivência que se dá no bojo social, isto porque, os vínculos não se reestruturam apenas nas formas, nos museus, encontram-se na transpiração da cultura, como referência Galeano "mais do que nos museus, onde os pobres se entendiam, a memória está no ar que respiramos; e ela, no

ar,

nos

respira"

$(1999$,

p.216).

\section{Conclusões}

As transformações provocadas pela construção da Usina Hidrelétrica de Itaipu ecoaram pela dimensão sociocultural, intervindo no processo da memória e da identidade. Por meio desta investigação inicial, pode-se dizer que as memórias se encontram submersas não apenas pelas águas, mas também pela falta de suportes que contemplem toda a história, valorizando a memória coletiva social das comunidades. No cotidiano, há uma manutenção, quase invisível, da memória, das experiências vividas que ficaram pelo caminho, que os meios oficiais deixaram de contar (SANTOS, 2006).

A memória enquanto elemento vivo "procura salvar o passado para servir o presente e o futuro" (LE GOFF, 1996, p.477). A partir das vicissitudes do presente se reconhece o passado, e aos poucos este se torna senso comum e segue permeando o entendimento e a cultura até solidificar-se. Assim, o passado passa a ser um instrumento de valor.

Ao entender o processo da construção da Usina Hidrelétrica Itaipu tendo a memória como pano de fundo, identificou-se que é fundamental incorporar as memórias coletivas à história, visto que, se o indivíduo não conhece o todo, não pode posicionar-se de forma consciente. Cabe a memória a nobre função de servir para o ser humano como elemento de libertação e não o contrário (LE GOFF, 1996).

Vale apontar que esta é uma pesquisa inicial sobre enquadramento da memória no processo de formação do Reservatório de Itaipu, portanto, abre para a necessidade de ampliar a investigação por meio da história oral.

Muitas memórias estão vivas, mas submersas, e dependendo do estímulo que recebem, podem emergir. O que preocupa é que os direitos humanos não aportam o direito de lembrar e, a cada ano que passa, as lembranças estão na iminência de desaparecer. É preciso aprender a lidar com o passado e equilibrar memória e esquecimento para cumprir com o papel de ser justo com quem viveu e quem aprenderá com as memórias.

\section{Referências}

BENJAMIN, W. Obras Escolhidas II - Rua de mão única Mão Única. Trad. Rubens Rodrigues Torres Filho, José Carlos Martins Barbosa. 3. ed. Obras escolhidas. v. 2. São Paulo: Brasiliense, 1993.

BOURDIEU, P. O poder simbólico. $4^{\circ}$ Ed. Rio de Janeiro: Bertrand Brasil, 2001.

D’ALESSIO, M. M. Memória: leituras de M. Halbwachs e P. Nora. Revista Brasileira de História, São Paulo, 13 (25/26);97-103, set.92 /ago. 1993.

GALEANO, E. De pernas para o ar: a escola do mundo ao avesso. Porto Alegre: L\&PM, 1999. 
GERMANI, G. I. Expropriados, Terra e água: o conflito de Itaipu. Salvador: $2^{\mathrm{a}}$ Ed. EDUFBA/ULBRA, 2003.

GROSSMAN, J. Violência e silêncio: Reescrevendo o futuro. História Oral, Revista da Associação Brasileira de História Oral, 2000.

HALBWACHS, M. A memória coletiva. $2^{\circ}$ Ed. São Paulo, Editora Centauro: Beatriz Sidou, 2003.

ITAIPU BINACIONAL. Site oficial. Disponível em: https://www.itaipu.gov.br. Acesso em 10 de jan.2016.

LE GOFF, J. História e memória. $4^{\circ}$ Ed. São Paulo: Editora Unicamp: Bernardo Leitão, 1996.

MAZZAROLLO, J. A Taipa da Injustiça: esbanjamento econômico, drama social e holocausto ecológico em Itaipu. $2^{a}$ Ed. São Paulo: Edições Loyola, 2003.

PELEGRINI, S. Cultura e Natureza: Os desafios das práticas preservacionistas na esfera do patrimônio cultural e ambiental. In: Revista Brasileira, 2006.

POLLAK, M. Memória, esquecimento, silêncio. In: Estudos Históricos, Rio de Janeiro: vol. 2, $\mathrm{n}^{\mathrm{o}} 3,1989$.

10, 1992.

. Memória e identidade social. In: Estudos Históricos, Rio de Janeiro, vol. 5, nº

RIBEIRO, M.F.B. Memórias do concreto: vozes na construção de Itaipu. Cascavel: Edunioeste, 2002.

SAMUEL, R. Teatros da Memória, In: Projeto história 4. São Paulo: Educ.1989.

SANTOS, A. P. Lago de memórias: a submersão das Sete Quedas, 2006.

SOUZA, E. B. C. de. Tríplice Fronteira: Fluxos da região Oeste do Paraná com o Paraguai e Argentina. In: Revista Terra, 2008. 